around the ecliptic, being least pronounced probably when a minimum falls in an equinoctial month. A hasty comparison of Dr. Wolfer's relative sun-spot numbers with the rainfall data of a few widely separated stations appears to hold out some encouragement for treating the data in this way.

L. G. Schultz.

Oficina Meteorológica Argentina, Observatorio

Magnético, Pilar, Córdoba, January I6.

\section{Concentric Joints in Ice.}

Is NATURE for January 25 a correspondent directed attention to concentric joints and bulbs which he noticed in the thin ice-sheets which covered several small partially dried-up pools, and stated that he would like to have an explanation of their cause.

I have seen circular ribs on the underside of icesheets on small pools which would appear to have been formed as shown by the accompanying diagram.

When the pool was full of water, a thin sheet of ice formed between $A$ and $B$. As the water sank into the ground an air space aa formed near the margins, the ice at the same time sagging. During the frost the further inward spread of the air space was arrested for a time by the freezing of the ring $b b$. Soon, however, in spite of the growth of the ring, the fall of the water-level allowed the air space

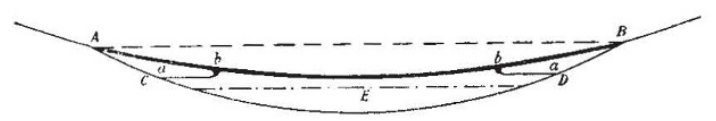

a a suddenly to increase in size, and another ring was then formed inside the first, the process being repeated several times, until the water-level fell to $E$ clear of the ice. From the water surface evaporation took place, and the vapour condensed on the underside of the ice-sheet, thickened it and made the ridges more pronounced and bulb-like.

The number of rings and the thickness of the ice depend upon the keenness of the frost and the rate at which the water-level falls.

A similar structure can be produced by perforations in thin ice-sheets partially supported by vegetation. The innermost ring is then the one first formed.

The fact that lines of weakness are produced above each rib is interesting, but has escaped my notice.

Inglewood, Longcroft Avenue, Harpenden.

\section{R. M. Dieley.}

\section{Remuneration of Public Analysts.}

Ox behalf of the Association of Chemical Technologists, I beg to enter a strong protest against the course of action that is being followed by the Lambeth and Wandsworth Borough Councils in regard to the filling of the appointments of public analyst for those boroughs which have become vacant by the death of Dr. John Muter.

The terms of remuneration offered by both these borough councils are far below the lowest of the very inadequate rates of payment made to public analysts in London and throughout the country, and the acceptance of such appointments by a qualified scientific chemist on such terms would be degrading to the chemical profession and detrimental in the highest degree to the interests of the public. On the terms offered, it is absolutely impossible that the NO. 22 I I, VOL. 89] responsible duties attaching to such appointments can be efficiently performed. A public analyst has great personal responsibility, his position is one of considerable anxiety, the value of his work is not generally understood, and the office he holds is widely disliked, for he is appointed under the provisions of Acts of Parliament which are extremely unpopular amony certain sections of the community. It is therefore essential that he should be in a position of such independence that he may not be liable to influence or pressure from any persons whose interest it may be to prevent, so far as possible, the effective administration of the Acts. It must be remembered, too, that with the enormous increase in scientific adulteration, the work of a public analyst is to-day very different from the work required even ten years ago, and it is therefore all the more necessary that the general public for whose protection the Acts were passed should appreciate the advisability of preventing the ever-increasing attempts of local authorities of a certain type to reduce the remuneration of the scientific officers concerned to a level rendering the satisfactory discharge of their duties impossible.

J. Wilberforce Grefin (Secretary).

30 Victoria Street, Westminster, London, S.W. March 6.

\section{The Storm of March 4.}

IN NAture of March 7 reference is made to the storm of March 4, and figures are quoted giving the velocity of the wind recorded at several stations. It would appear that the storm attained a greater velocity here than at either of the stations named, and a ferv particulars of the record made by the Dines pressure-tube anemometer erected at Pendennis Castle, Falmouth, by the Meteorological Office, may be of interest.

On the morning of March 4 a progressive mean velocity of from 20 to 50 miles an hour was recorded; at 6 p.m. it had increased to 65 miles per hour, and this velocity was maintained to midnight. The squalls were very violent; between 2 p.m. and midnight a maximum velocity of 80 miles or more was registered more than twenty times, whilst the greatest squall attained a velocity of 98 miles at 6 p.n. This has been but once exceeded (or reached) since the anemometer was erected in 1902 , viz. I03 miles at I I.30 p.m. of March I4, I905.

EDIVARD KitTo (Superintendent).

The Observatory, Falmouth, March Ir.

\section{Observed Fall of an Aërolite near St. Albans.}

DURING a heavy thunderstorm which ensued on Monday, March 4, between 2.30 p.m. and 4.I5 p.m., an aërolite was observed to fall at Colney Heath, near St. Albans. The observer, who has placed the specimen in my hands for examination, stated that the stone fell within a few feet from where he was standing, and that it entered the ground for a distance of about $3 \mathrm{ft}$. Its fall was accompanied by an unusually heavy clap of thunder. The example weighs $51 \mathrm{~b}$. I $4 \frac{1}{2}$ Oz., and measures $6 \frac{3}{4}$ in. $\times 5^{\frac{5}{8}}$ in. at its greatest length and breadth respectively. The mass is irregularly ovate on the one side, and broken in outline on the other. The actual surface throughout is fairly deeply pitted, and under magnification exhibits the usual chondritic structure of the crystalline matter, with interspersed particles of what appears to be nickeliferous iron.

Hertfordshire Museum, St. Albans. 